\title{
Treadmill exercise inhibits apoptotic neuronal cell death with suppressed vascular endothelial growth factor expression in the retinas of the diabetic rats
}

\author{
Eun-Sang Ji' ${ }^{1}$ II-Gyu Ko ${ }^{2}$, Jung-Wan Cho² , Ronald W. Davis ${ }^{3}$, Gwang-Yon Hwang ${ }^{3}$, Yong-Seok Jee ${ }^{4}$, Baek-Vin Lim,* \\ 'Department of Sport \& Health Science, College of Natural Science, Sangmyung University, Seoul, Korea \\ ${ }^{2}$ Department of Physiology, College of Medicine, Kyung Hee University, Seoul, Korea \\ ${ }^{3}$ Department of Kinesiology, College of Health Sciences, Texas Woman's University, Texas, USA \\ ${ }^{4}$ Department of Leisure Sports, College of Science, Hanseo University, Seosan, Korea \\ ${ }^{5}$ Department of Exercise Prescription, Division of Leisure \& Sports Science, Dongseo University, Busan, Korea
}

Diabetic retinopathy is one of the most important microvascular complications in diabetes, and it is the major cause of visual loss. Physical exercise is known to ameliorate the symptoms of metabolic syndromes such as diabetic mellitus. In the present study, we investigated the effects of treadmill exercise on vascular endothelial growth factor (VEGF) expression and apoptotic cell death in the retinas of streptozotocin (STZ)induced diabetic rats. The male Sprague- Dawley rats were randomly divided into three groups ( $n=10$ in each group): control group, STZ-induce diabetes group, STZ-induced diabetes and treadmill exercise group. To induce diabetes in the experimental animals, a single intraperitioneal injection of STZ $(50 \mathrm{mg} / \mathrm{kg}$ ) was given to each animal. The rats in the exercise group were forced to run on a motorized treadmill for 30 min once a day during 1 week starting 6 weeks after STZ injec- tion. In the present results, VEGF expression in the retinas was increased by induction of diabetes. The numbers of caspase-3-positive and terminal deoxynucleotidyl transferase-mediated dUTP nick end labeling (TUNEL)positive cells in the retinas were also enhanced by induction of diabetes. Treadmill exercise significantly decreased VEGF expression and suppressed the number of TUNEL-positive and caspase-3-positive cells in the retinas of diabetic rats. In the present study, we have shown that treadmill exercise might alleviate the progression of diabetic retinopathy through suppressing VEGF expression and apoptotic cell death in the retinas of the diabetic rats.

Keywords: Diabetic retinopathy, Streptozotocin, Vascular endothelial growth factor, Apoptosis

\section{INTRODUCTION}

Diabetes mellitus is a chronic metabolic disease characterized by elevated blood glucose level, and this disease is resulted by inability to produce insulin or by the resistance to insulin action. Complications of the diabetes can be classified as microvascular and macrovascular complications (Deshpande et al., 2008). Microvascular complications include nervous system damage (neuropathy), renal system damage (nephropathy), and eye damage (retinopathy). Macrovascular complications include cardiovascular diseases, stroke, and peripheral vascular diseases.
Diabetic retinopathy is the most common complication of diabetes. Its prevalence rate is about $90 \%$ or more, and it progresses to legal blindness in approximately $5 \%$ of diabetic patients $(\mathrm{Ku}-$ sari et al., 2007). Most of cases, diabetic retinopathy has no early warning signs. Diabetic retinopathy has been considered as a microvascular disease, and the breakdown of blood retinal barrier is an important feature of this disease (Leal et al., 2005). Diabetic retinopathy has also been considered as a neurodegenerative disease of the retinas (Kusari et al., 2007). Diabetic retinopathy is characterized by neovascularization originating from the retinas and optic disk. Hyperglycemia induces damage to the retinal vas-
${ }^{*}$ Corresponding author: Baek-Vin Lim

Department of Exercise Prescription, Division of Leisure \& Sports Science,

Dongseo University, 47 Jurye-ro, Sasang-gu, Busan 617-716, Korea

Tel: +82-51-320-1887, Fax: +82-51-320-1945, E-mail: todd64@naver.com

Received: June 7, 2013 / Revised: June 14, 2013 / Accepted: June 23, 2013
This is an Open Access article distributed under the terms of the Creative Commons Attribution Non-Commercial License (http://creativecommons.org/licenses/by-nc/3.0/) which permits unrestricted non-commercial use, distribution, and reproduction in any medium, provided the original work is properly cited. 
culature, and progression of diabetic retinopathy is related to the severity and duration of hyperglycemia. The exact mechanisms on the how the raised glucose level induces vascular distuption in the retinas are still poorly defined (Shah, 2008). Many growth factors are known to be implicated in the development of structural changes of the retinal vasculature (increased retinal vascular permeability, retinal ischemia, neovascularisation) and in the progression of diabetic retinopathy (Aiello et al., 2001). Vascular endothelial growth factor (VEGF) has also been suggested as one on the etiological factors of diabetic retinopathy.

VEGF is a potent angiogenic and vascular hyperpermeability factor, and it plays a crucial role in the pathogenesis of diabetic retinopathy (Qaum et al., 2001). VEGF is produced form the retinal pigment epithelium cells, ganglion cells, Müller cells, smooth muscle cells in the human retinas and choroids, and VEGF expression is mainly regulated by tissue oxygen content (Ishida et al., 2003).

Apoptosis is known as the programmed cell death and it plays a crucial role in the development and maintenance of homeostasis in all multicellular organisms (Gavrieli et al., 1992; Thompson, 1995). Apoptosis constitutes part of a common mechanism in cell replacement, tissue remodeling, and removal of damaged cells (Thompson, 1995). Terminal deoxynucleotidyl transferase-mediated dUTP nick end labeling (TUNEL) staining is an assay that detects DNA fragmentation, which is characteristic of apoptotic cell death (Gavrieli et al., 1992). Caspase-3 is the most widely studied member of the caspases family, and it is one of key executors of apoptosis (Cohen, 1997). Apoptosis also plays a critical role in the pathogenesis of diabetic retinopathy (Wong, 1994). It was reported that diabetes induces damage to the nonvascular retinal neurons and Müller glial cells (Barber, 2003).

Exercise is known to improve glucose uptake by increasing insulin sensitivity (Kivelä et al., 2006), to increase the availability of glucose transporter- 4 (GLUT- 4 ) by translocation to the cell membrane (Henriksen, 2002) and by increased transcription in muscle cells (Dohm, 2002), and to improve vascular function of the diabetes patients (Fuchsjäger-Mayrl et al., 2002). Exercise is a treatment modality for the diabetes patients, however the effects of exercise on diabetic retinopathy in relation with VEGF expression and apoptosis in the retinas have not been clarified. In the present study, we investigated the effects of treadmill exercise on VEGF expression and apoptotic cell death in the retinas of the streptozotocin (STZ)-induced diabetic rats.

\section{MATERIALS AND METHODS}

\section{Animals and treatments}

The experimental procedures were performed in accordance with the animal care guidelines of the National Institutes of Health (NIH) and the Korean Academy of Medical Sciences. Male Sprague-Dawley rats weighing $200 \pm 10 \mathrm{~g}$ (7 weeks in age) were used in this experiment. The rats were housed under controlled temperature $\left(20 \pm 2^{\circ} \mathrm{C}\right.$ ) and lighting conditions (07:00 to 19:00 h), with food and water made available ad libitum throughout the experiments. The animals were randomly divided into three groups $(\mathrm{n}=10$ in each group): the control group, the STZ-induce diabetes group, and the STZ-induced diabetes and treadmill exercise group.

\section{Induction of diabetes}

To induce diabetes in the experimental animals, a single intraperitoneal injection of STZ $(50 \mathrm{mg} / \mathrm{kg}$, dissolved in $0.01 \mathrm{M}$ citrate buffer at pH 4.5; Sigma Chemical Co., St. Louis, MO, USA) was given to each animal. Blood glucose levels were determined 2 days after STZ injection using a blood glucose tester (Arkray, Kyoto, Japan). Only the animals with blood glucose levels of $300 \mathrm{mg} / \mathrm{dl}$ or higher were used as the diabetes groups. Blood glucose levels were measured on the $0,3,6$, and 7 weeks of the commencement of experiment.

\section{Treadmill exercise}

The rats in the exercise group were forced to run on a motorized treadmill for 30 min once a day for 1 week starting 6 weeks after STZ injection. The exercise load consisted of running at the speed of 2 meters $/ \mathrm{min}$ for the first $5 \mathrm{~min}, 5$ meters $/ \mathrm{min}$ for the next $5 \mathrm{~min}$, and then 8 meters $/ \mathrm{min}$ for the last $20 \mathrm{~min}$, with the $0^{\circ}$ inclination.

\section{Tissue preparation}

After finishing last exercise, half of the animals were anesthetized using Zoletil $50^{\circledR}(10 \mathrm{mg} / \mathrm{kg}$, i.p.; Vibac Laboratories, Carros, France), transcardially perfused with $50 \mathrm{mM}$ phosphate-buffered saline (PBS), and fixed with the freshly prepared solution consisting of $4 \%$ paraformaldehyde in $100 \mathrm{mM}$ phosphate buffer $(\mathrm{PB}, \mathrm{pH} 7.4)$. The retinas were dissected and postfixed in the same fixative overnight and then transferred into the $30 \%$ sucrose solution for cryoprotection. Coronal sections of $10 \mu \mathrm{m}$ thickness were made with a freezing microtome (Leica, Nussloch, Germany).

\section{Caspase-3 immunohistochemistry}

For the visualization of caspase- 3 expression, caspase-3 immu- 
nohistochemistry was performed as the previously described method (Kim et al., 2013; Ko et al., 2009). The sections were drawn from retinas and incubated overnight with mouse anti-caspase-3 antibody (1:500; Santa Cruz Biotechnology, Santa Cruz, CA, USA) and then for another $1 \mathrm{~h}$ with biotinylated mouse secondary antibody (1:200; Vector Laboratories, Burlingame, CA, USA). Bound secondary antibody was then amplified with Vector Elite $A B C$ kit $^{\circledR}$ (1:100; Vector Laboratories). The antibody-biotin-avidin-peroxidase complexes were visualized using $0.03 \%$ 3,3'-diaminobenzidine $(\mathrm{DAB})$, and the sections were finally mounted onto gelatin-coated slides. The slides were air dried overnight at room temperature, and coverslips were mounted using Permount ${ }^{\circledR}$ (Fisher Scientifc Company, Fair Lawn, NJ, USA).

\section{TUNEL staining}

For the visualization of DNA fragmentation, TUNEL staining was performed using In Situ Cell Death Detection Kit ${ }^{\circledR}$ (Roche, Mannheim, Germany) according to the manufacturer's protocol (Kim et al., 2013; Ko et al., 2009). The retinas were suspended in $10 \mathrm{mM}$ Tris- $\mathrm{HCl}$ buffer, $\mathrm{pH} 8.0$ containing $1 \mathrm{mM}$ EDTA by incubating at $55^{\circ} \mathrm{C}$ for $30 \mathrm{~min}$. Then, the sections were incubated with $5^{\circ} \mathrm{C}$ proteinase $\mathrm{K}(100 \mu \mathrm{g} / \mathrm{mL})$ rinsed, and incubated in $3 \%$ $\mathrm{H}_{2} \mathrm{O}_{2}$, permeabilized with $0.5 \%$ Triton X-100, rinsed again, and incubated in TUNEL reaction mixture. The sections were rinsed and visualized using Converter-POD with $0.03 \% \mathrm{DAB}$, and the sections were finally mounted onto gelatin-coated slides. The slides were air dried overnight at room temperature, and coverslips were mounted using Permount ${ }^{\circledR}$ (Fisher Scientific Company).

\section{Western blot for VEGF expression}

Western blot for VEGF expression was performed according to the previously described method (Kim et al., 2012). After finishing last exercise, the other of the animals were anesthetized using Zoletil $50^{\circledast}(10 \mathrm{mg} / \mathrm{kg}$, i.p.; Vibac Laboratories), and eyeballs were extruded, and retinas were lysed in a lysis buffer containing $50 \mathrm{mM}$ Tris- $\mathrm{HCl}$ (pH 7.5), $150 \mathrm{mM} \mathrm{NaCl}, 0.5 \%$ deoxycholic acid, $1 \%$ Nonidet P40, 0.1\% SDS, $1 \mathrm{mM}$ PMSF, and $100 \mathrm{mg} / \mathrm{mL}$ leupeptin. Protein content was measured using a Bio-Rad colorimetric protein assay kit (Bio-Rad, Hercules, CA, USA). Protein of $30 \mu \mathrm{g}$ was separated on SDS-polyacrylamide gels and transferred onto a nitrocellulose membrane (Schleicher \& Schuell GmbH, Dassel, Germany). Mouse anti-actin (1:1,000; Santa Cruz Biotechnology) and mouse anti-VEGF (1:1,000; Santa Cruz Biotech) were used as the primary antibodies. Horseradish peroxidase-conjugated anti-mouse antibody for VEGF (1:1,000; Santa Cruz Biotechnology) was used to probe for VEGF. Band detection was performed using the enhanced chemiluminescence (ECL) detection system (Santa Cruz Biotechnology).

\section{Data analysis}

The numbers of TUNEL-positive and caspase-3-positive cells in the retinas were counted through a light microscope (Olympus, Tokyo, Japan). The relative expressions of proteins were detected densitometrically using Molecular AnalystTM version 1.4.1 (BioRad). Statistical analysis was performed using one-way ANOVA followed by Duncan's post-hoc test. The results are expressed as the mean \pm standard error of the mean (SEM). Significance was set at $P<0.05$.

\section{RESULTS}

\section{Effects of treadmill exercise on body weight and blood glucose level}

The average weight was $209.00 \pm 4.51 \mathrm{~g}, 279.10 \pm 6.23 \mathrm{~g}, 320.50$ $\pm 4.77 \mathrm{~g}$, and $327.20 \pm 4.72 \mathrm{~g}$ in the control group, $200.00 \pm 4.38$ g, $245.00 \pm 3.11 \mathrm{~g}, 265.40 \pm 4.44 \mathrm{~g}$, and $261.61 \pm 4.34 \mathrm{~g}$ in the STZ-induced diabetes group, $207.00 \pm 4.72 \mathrm{~g}, 256.40 \pm 4.33 \mathrm{~g}$, $260.60 \pm 4.34 \mathrm{~g}$, and $269.10 \pm 3.68 \mathrm{~g}$ in the STZ-induced diabetes and treadmill exercise group on the $0,3,6$, and 7 weeks of the experiment, respectively. In the diabetes group, retardation of weight gain was observed $(P<0.05)$, in contrast, the rats in the control groups showed increase in weight gain $(P<0.05)$. Treadmill exercise for 1 week exerted no significant effect on weight gain in the diabetic rats.

The blood glucose level was $125.66 \pm 5.40 \mathrm{mg} / \mathrm{mL}, 126.40 \pm$ $6.10 \mathrm{mg} / \mathrm{mL}, 119.33 \pm 2.94 \mathrm{mg} / \mathrm{mL}$, and $118.60 \pm 3.10 \mathrm{mg} / \mathrm{mL}$ in the control group, $120.33 \pm 4.60 \mathrm{mg} / \mathrm{mL}, 461.60 \pm 16.10 \mathrm{mg} /$ $\mathrm{mL}, 469.39 \pm 19.33 \mathrm{mg} / \mathrm{mL}$, and $460.75 \pm 12.05 \mathrm{mg} / \mathrm{mL}$ in the STZ-induced diabetes group, $119.33 \pm 3.61 \mathrm{mg} / \mathrm{mL}, 466.30 \pm$ $18.90 \mathrm{mg} / \mathrm{mL}, 453.20 \pm 16.22 \mathrm{mg} / \mathrm{mL}$, and $419.36 \pm 10.90 \mathrm{mg} /$ $\mathrm{mL}$ in the STZ-induced diabetes and treadmill exercise group on the $0,3,6,7$ weeks of the experiment, respectively. The blood glucose level was increased in the diabetic rats $(P<0.05)$. The blood glucose in the diabetic rats was not significantly decreased in response to the treadmill exercise for 1 week.

\section{Effects of treadmill exercise on VEGF expression in the retinas}

Photomicrographs of VEGF expression in the retinas are presented Fig. 1. When the level of VEGF protein in the control 


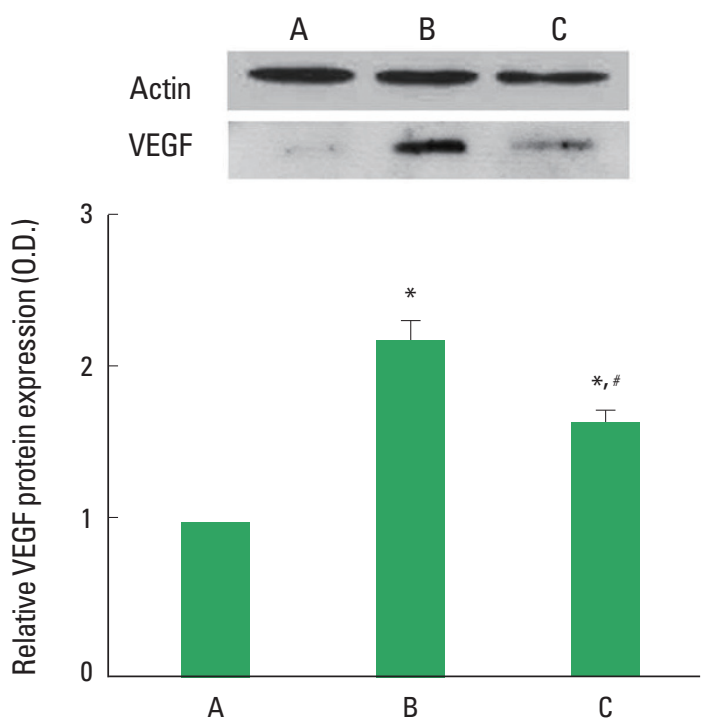

Fig. 1. Effect of treadmill exercise on VEGF protein expression in the retinas. Upper: Representative expression of the protein level of VEGF in the retina. Lower: The density of VEGF protein expression in each group. (A) Control group, (B) STZ-induced diabetes group, (C) STZ-induced diabetes and treadmill exercise group. The data are represented as the mean \pm SEM. ${ }^{*}$ means $P<0.05$ compared to the control group. "means $P<0.05$ compared to the STZ-induced diabetes group.

group was set at 1.00, the level of VEGF protein was $2.20 \pm 0.13$ in the STZ-induced diabetes group and $1.67 \pm 0.08$ in the STZinduced diabetes and treadmill exercise group. The present result showed that STZ-induced diabetes increased the level of VEGF in the retinas $(P<0.05)$ and treadmill exercise decreased the expression of VGEF in the retinas of the diabetic rats $(P<0.05)$.

\section{Effects of treadmill exercise on DNA fragmentation in the retinas}

Photomicrographs of TUNEL-positive cells in the retinas are presented in Fig. 2. The number of TUNEL-positive cells was $3.90 \pm 0.67 /$ section in the control group, $48.60 \pm 5.43 /$ section in the STZ-induced diabetic group, and 31.45 $\pm 3.61 /$ section in the STZ-induced diabetes and treadmill exercise group. These results showed that STZ-induced diabetes enhanced apoptotic cell death in the retinas $(P<0.05)$ and treadmill exercise suppressed the apoptosis in the retinas of the diabetic rats $(P<0.05)$.

\section{Effects of treadmill exercise on caspase-3 expression in the retinas}

Photomicrographs of caspase-3-positive cells in the retinas are presented in Fig. 3. The number of caspase-3-positive cells was
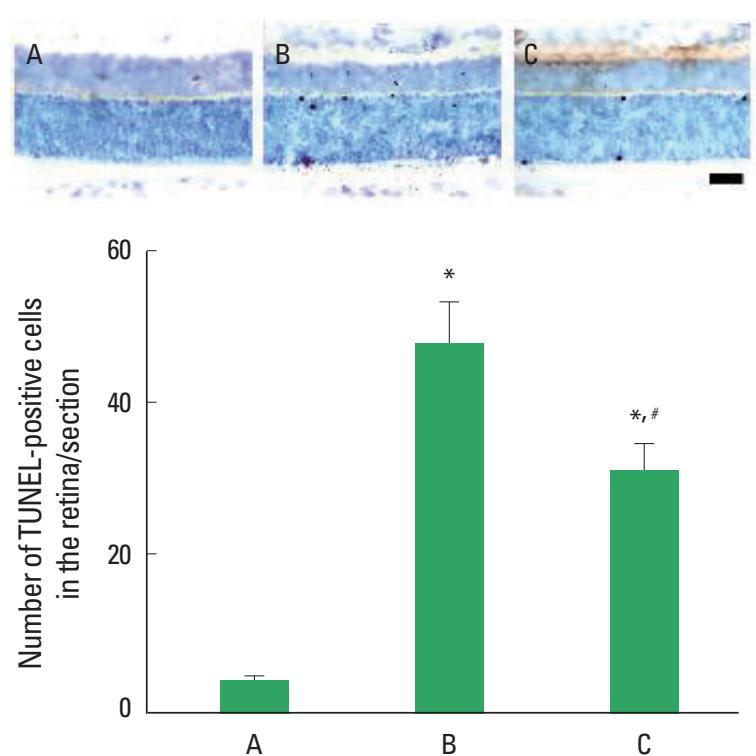

Fig. 2. Effect of treadmill exercise on TUNEL-positive cells in the retinas. Upper: Photomicrographs of TUNEL-positive cells in the retina. The scale bar represents $400 \mu \mathrm{m}$. Lower: Number of TUNEL-positive cells in each group. (A) Control group, (B) STZ-induced diabetes group, (C) STZ-induced diabetes and treadmill exercise group. The data are represented as the mean \pm SEM. ${ }^{*}$ means $P<0.05$ compared to the control group. " means $P<0.05$ compared to the STZinduced diabetes group.

$4.30 \pm 0.91 /$ section in the control group, $38.47 \pm 5.88 /$ section in the STZ-induced diabetes group, and $23.10 \pm 2.91$ /section in the STZ-induced diabetes and treadmill exercise group. These results showed that STZ-induced diabetes enhanced caspase- 3 expression in the retinas $(P<0.05)$ and treadmill exercise suppressed the caspase- 3 expression in the retinas of the diabetic rats $(P<0.05)$.

\section{DISCUSSION}

Diabetes mellitus is closely associated with multiple secondary complications, including cardiovascular diseases, kidney failure, neuropathy, retinopathy, and cataracts. Among them, diabetic retinopathy is a major complication of the diabetic patients (Laaksonen et al., 2004). In diabetic retinopathy, VEGF is the predominant cytokine that accelerates vascular permeability and endothelial cell growth (Witmer et al., 2003). VEGF expression of the retinas was significantly increased in the STZ-induced diabetic rats (Murata et al., 1995; Kim et al., 2012). VEGF plays an important role in blood-retinal barrier breakdown in diabetic retinopathy and inhibition of VEGF expression prevented neovascularization and blood-retinal barrier breakdown (Masuzawa et al., 2006). Aerobic exercise training is known to improve the vascular endothelial function in type I diabetes patients, who were substan- 

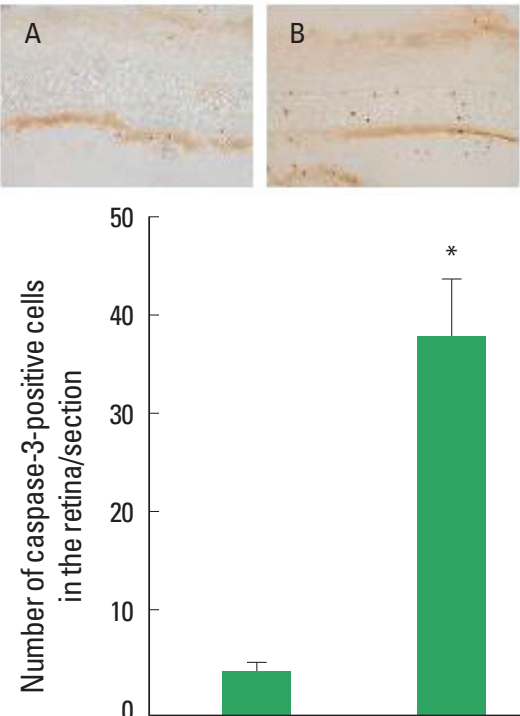

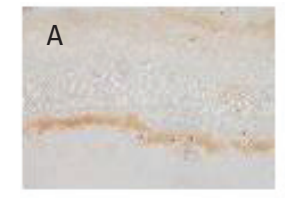

50
40
30
20
10
0
A

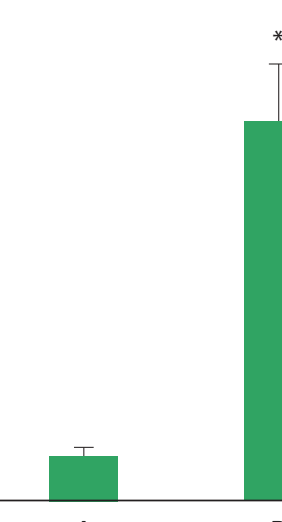

B

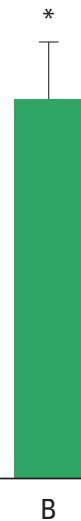

C
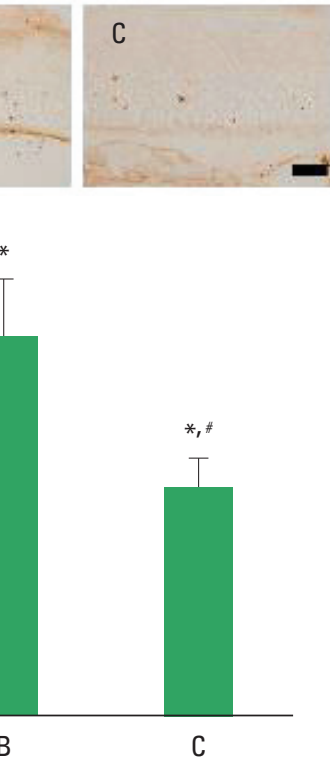

C
Fig. 3. Effect of treadmill exercise on caspase-3 expression in the retinas. Upper: Photomicrographs of caspase-3-positive cells in the retina. The scale bar represents $400 \mu \mathrm{m}$. Lower: Number of caspase-3-positive cells in each group. (A) Control group, (B) STZ-induced diabetes group, (C) STZ-induced diabetes and treadmill exercise group. The data are represented as the mean \pm SEM. ${ }^{*}$ means $P<0.05$ compared to the control group. "means $P<0.05$ compared to the STZ-induced diabetes group.

tial risk for diabetic angiopathy (Fuchsjäger-Mayrl et al., 2002). VEGF inhibition can be considered as a promising therapeutic approach to some tumoral and ocular diseases (Corvol et al., 2008). Enhanced VEGF expression in the retinas of diabetic rats was suppressed by treadmill exercise, meanwhile VEGF expression in the retinas of normal rats was not changed by treadmill exercise (Kim et al., 2012).

In the present study, VEGF expression in the retinas was increased in the STZ-induced diabetic rats. The present results suggest that induction of diabetes increases neovascularization through enhancing of VEGF expression in the retinas. Treadmill exercise suppressed diabetes-induced increase of VEGF expression in the retinas. Such suppressive effect of exercise on VEGF expression might inhibit progression of diabetic retinopathy.

Retina degeneration leads to diabetic retinopathy and eventually causes visual loss. In particular, retinal neuropathy increases apoptosis of retinal ganglion cells and induces abnormal metabolic changes of retinal glial cells (Barber, 2003; Fletcher et al., 2005). High glucose level enhanced apoptosis in retinal endothelial cells (Du et al., 2003; Kowluru and Abbas, 2003; Kowluru and Koppolu, 2002). Park et al. (2003) reported that visual loss associated with diabetic retinopathy could be attributed to an early phase of photoreceptor loss in the STZ-induced diabetic rats. Apoptosis of retinal cells is a consummated phenomenon in diabetic retinopathy, and retinal capillary cells undergo accelerated apoptosis (Mizutani et al., 1996). In additions, oxidative stress contributes to the development of diabetic retinopathy (Kowluru and Chan, 2007). Several studies reported that mitochondria function under oxidative stress could contribute to apoptosis and increased oxidative stress might modulate retinal cell apoptosis in diabetes via caspase-3 pathway (Kowluru and Chan, 2007). Anti-apoptotic effect of treadmill exercise on retinas was well documented (Abu El Asrar et al., 2004; Gao et al., 2009). Kim et al. (2013) reported that treadmill exercise ameliorated apoptosis in the retinas through enhancing the level of phophorylated protein kinase B (p-Akt) in diabetic rats.

In the present study, the numbers of TUNEL-positive and caspase-3-positive cells in the retina were significantly increased in STZ-induced diabetic rats. However, exercise significantly suppressed both the STZ-induced increase in DNA fragmentation and caspase- 3 expression in the retinas. The present results revealed that treadmill exercise alleviated diabetes-induced apoptotic cell death in the retinas.

The beneficial effects of physical exercise for the individuals with diabetes meillitus include decrease of risk of diabetes-related complications and mortality (Rachmiel et al., 2007). In the present study, we demonstrated that treadmill exercise decreased VEGF expression and suppressed apoptotic cell death in the retinas of diabetic rats. Based on the present results, treadmill exercise may the helpful strategy for the alleviating symptoms and complications of diabetic retinopathy.

\section{CONFLICT OF INTEREST}

No potential conflict of interest relevant to this article was reported.

\section{REFERENCES}

Abu El Asrar AM, Dralands L, Missotten L, AI-Jadaan IA, Geboes K. Expression of apoptosis markers in the retinas of human subjects with diabetes. Invest Ophthalmol Vis Sci 2004;45:2760-2766.

Aiello LP, Cahill MT, Wong JS. Systemic considerations in the management of diabetic retinopathy. Am J Ophthalmol 2001;132:760-776.

Barber AJ. A new view of diabetic retinopathy: a neurodegenerative disease of the eye. Prog Neuropsychopharmacol Biol Psychiatry 2003;27: 283-290. 
Cohen GM. Caspases: the executioners of apoptosis. Biochem J 1997;326:116.

Corvol P. VEGF, anti-vEGF and diseases. Bull Acad Natl Med. 2008;192: 289-300; discussion 300-302

Deshpande AD, Harris-Hayes M, Schootman M. Epidemiology of diabetes and diabetes-related complications. Phys Ther 2008;88:1254-1264.

Dohm L. Invited review: regulation of skeletal muscle GLUT-4 expression by exercise. J Appl Physiol 2002;93:782-787.

Du Y, Miller CM, Kern TS. Hyperglycemia increases mitochondrial superoxide in retina and retinal cells. Free Radic Biol Med 2003;35:1491-1499.

Fletcher EL, Phipps JA, Wilkinson-Berka JL. Dysfunction of retinal neurons and glia during diabetes. Clin Exp Optom 2005;88:132-145.

Fuchsjäger-Mayrl G, Pleiner J, Wiesinger GF, Sieder AE, Quittan M, Nuhr MJ, Francesconi C, Seit HP, Francesconi M, Schmetterer L, Wolzt M. Exercise training improves vascular endothelial function in patients with type 1 diabetes. Diabetes Care 2002;25:1795-1801.

Gao XY, Kuang HY, Zou W, Liu XM, Lin HB, Yang Y. The timing of re institution of good blood glucose control affects apoptosis and expression of Bax and Bcl 2 in the retina of diabetic rats. Mol Biol Rep 2009; 36:1977-1982.

Gavrieli Y, Sherman Y, Ben-Sasson SA. Identification of programmed cell death in situ via specific labeling of nuclear DNA fragmentation. J Cell Biol 1992;119:493-501.

Henriksen EJ. Invited review: Effects of acute exercise and exercise training on insulin resistance. J Appl Physiol 2002;93:788-796.

Ishida S, Usui T, Yamashiro K, Kaji Y, Ahmed E, Carrasquillo KG, Amano S, Hida T, Oguchi Y, Adamis AP. VEGF164 is proinflammatory in the diabetic retina. Invest Ophthalmol Vis Sci 2003;44:2155-2162.

Kim DY, Kim TW, Kim CJ, Jung SY. Effect of treadmill exercise on modulation of vascular endothelial growth factor in the retina of diabetic rats. Korean J Phys Educ 2012;51:363-372.

Kim DY, Jung SY, Kim CJ, Sung YH, Kim JD. Treadmill exercise ameliorates apoptotic cell death in the retinas of diabetic rats. Mol Med Rep 2013;7:1745-1750.

Kivelä R, Silvennoinen M, Touvra AM, Lehti TM, Kainulainen H, Vihko V. Effects of experimental type 1 diabetes and exercise training on angiogenic gene expression and capillarization in skeletal muscle. FASEB J 2006;20:1570-1572.

Ko IG, Shin MS, Kim BK, Kim SE, Sung YH, Kim TS, Shin MC, Cho HJ, Kim SC, Kim SH, Kim KH, Shin DH, Kim CJ. Tadalafil improves shortterm memory by suppressing ischemia-induced apoptosis of hippocampal neuronal cells in gerbils. Pharmacol Biochem Behav 2009;91: 629-635.

Kowluru RA, Abbas SN. Diabetes-induced mitochondrial dysfunction in the retina, Invest. Ophthalmol Vis Sci 2003;44:5327-5334.

Kowluru RA, Chan PS. Oxidative stress and diabetic retinopathy. Exp Diabetes Res 2007;2007:43603.

Kowluru RA, Koppolu P. Diabetes-induced activation of caspase-3 in retina: effect of antioxidant therapy. Free Radic Res 2002;36:993-999.

Kusari J, Zhou S, Padillo E, Clarke KG, Gil DW. Effect of memantine on neuroretinal function and retinal vascular changes of streptozotocin-induced diabetic rats. Invest Ophthalmol Vis Sci 2007;48:5152-5159.

Laaksonen DE, Niskanen L, Punnonen K, Nyyssönen K, Tuomainen TP, Valkonen VP, Salonen R, Salonen JT. Testosterone: and sex hormonebinding globulin predict the metabolic syndrome and diabetes in middle-aged men. Diabetes Care 2004;27:1036-1041.

Leal EC, Santiago AR, Ambrosio AF. Old and new drug targets in diabetic retinopathy: from biochemical changes to inflammation and neurodegeneration. Curr Drug Targets CNS Neurol Disord 2005;4:421-434.

Masuzawa K, Jesmin S, Maeda S, Zaedi S, Shimojo N, Miyauchi T, Goto K. Effect of endothelin dual receptor antagonist on VEGF levels in streptozotocin -induced diabetic rat retina. Exp Biol Med (Maywood) 2006;231:1090-1094.

Mizutani M, Kern TS, Lorenzi M. Accelerated death of retinal microvascular cells in human and experimental diabetic retinopathy. J Clin Invest 1996;97:2883-2890.

Murata T, Ishibashi T, Khalil A, Hata Y, Yoshikawa H, and Inomata H. Vascular endothelial growth factor plays a role in hyperpermeability of diabetic retinal vessels. Ophthalmic Res 1995;27:48-52.

Park SH, Park JW, Park SJ, Kim KY, Chung JW, Chun MH, Oh SJ. Apoptotic death of photoreceptors in the streptozotocin-induced diabetic rat retina. Diabetologia 2003;46:1260-1268.

Qaum T, Xu Q, Joussen AM, Clemens MW, Qin W, Miyamoto K, Hassessian H, Wiegand SJ, Rudge J, Yancopoulos GD, and Adamis AP. VEGFinitiated blood-retinal barrier breakdown in early diabetes. Invest Ophthalmol Vis Sci 2001;42:2408-2413.

Rachmiel M, Buccino J, Daneman D. Exercise and type 1 diabetes mellitus in youth; review and recommendations. Pediatr Endocrinol Rev 2007; 5:656-665.

Shah CA. Diabetic retinopathy: A comprehensive review. Indian J Med Sci 2008;62:500-519.

Thompson CB. Apoptosis in the pathogenesis and treatment of disease. Science 1995;267:1456-1462.

Witmer AN, Vrensen GFJM, Van Noorden CJF, and Schlingemann RO. Vascular endothelial growth factors and angiogenesis in eye disease. Prog Retinal Eye Res 2003;22:1-29.

Wong P. Apoptosis, retinitis pigmentosa, and degeneration. Biochem Cell Biol 1994;72:489-498. 